Revista Destaques Acadêmicos, Lajeado, v. 9, n. 3, 2017. ISSN 2176-3070

DOI: http://dx.doi.org/10.22410/issn.2176-3070.v9i3a2017.1394

www.univates.br/revistas

\title{
ESQUEMA VACINAL DE HEPATITE B EM PROFISSIONAIS DE ENFERMAGEM DE UM HOSPITAL DE MÉDIO PORTE
}

\author{
Anelise Carvalho Rauber ${ }^{1}$, Paula Michele Lohmann², Luís Felipe Pissaia ${ }^{3}$, \\ Arlete Eli Kunz da Costa ${ }^{4}$
}

\begin{abstract}
Resumo: O objetivo da pesquisa foi de conhecer o esquema vacinal contra Hepatite B dos profissionais de enfermagem de um hospital de médio porte do interior do Rio Grande do Sul. A obtenção dos níveis séricos de anticorpos anti-HBs deu-se através de uma pesquisa documental. Foi constatada uma soroconversão (de 10,00 a 100,00 $\mathrm{UI} / \mathrm{ml}$ ) presente em $29,10 \%$ dos indivíduos, uma soroproteção (acima de 100,00UI/ $\mathrm{mL}$ ) ocorrendo em 46,27\% dos indivíduos, e uma hiper-proteção (acima de 1000,00UI/ $\mathrm{mL}$ ) em $20,15 \%$. Utilizando como valor de corte $10 \mathrm{UI} / \mathrm{ml}$, obteve-se uma média efetiva de $95,52 \%$ dos indivíduos. Constatou-se uma alta taxa de adesão dos funcionários (96,27\%), e que estudos envolvendo a vacinação anti-HBs devem levar em conta o maior número possível de fatores para a determinação de suas análises, além da importância da vacinação para a segurança dos profissionais da área.
\end{abstract}

Palavras-chave: Hepatite B. Esquema Vacinal. Enfermeiros.

\section{INTRODUÇÃO}

A exposição ocupacional a material biológico representa um risco para os trabalhadores das instituições de saúde devido à possibilidade de transmissão de patógenos. Os riscos para a saúde originados durante o trabalho não podem ser atribuídos a uma causa simples, mas a um conjunto de fatores presentes no ambiente, que se combinam a ponto de potencializarem seus efeitos.

1 Enfermeira. Universidade do Vale do Taquari - Univates. Lajeado - RS - Brasil.

2 Enfermeira. Mestre em Ambiente e Desenvolvimento. Universidade do Vale do Taquari Univates. Lajeado - RS - Brasil.

3 Enfermeiro. Mestrando em Ensino. Universidade do Vale do Taquari - Univates. Lajeado - RS - Brasil.

4 Enfermeira. Doutora em Ambiente e Desenvolvimento. Universidade do Vale do Taquari Univates. Lajeado - RS - Brasil. 
Neste contexto, os trabalhadores da área da enfermagem apresentam riscos à sua saúde inerentes à função que desempenham em suas atividades diárias. Em função desta peculiaridade vários trabalhos são voltados aos riscos ocupacionais no meio hospitalar. Para limitar a probabilidade de transmissão de certas doenças infecciosas neste meio, muitos países adotam programas de imunizações com atenção especial para o pessoal da saúde (BULHÕES, 1998).

A imunização dos profissionais é o mais eficiente procedimento de prevenção específico contra doenças transmissíveis de risco ocupacional. A vacinação é uma das medidas mais importantes de prevenção contra este tipo de doenças, sendo muito mais fácil e tendo um menor custo financeiro prevenir uma doença do que tratá-la. A vacinação não protege somente o indivíduo que recebe a vacina, mas também protege a comunidade (TOSCANO; KOSIM, 2003).

E a vacinação contra a Hepatite $B$, doença infecciosa viral, é ainda a forma mais eficaz de proteger-se da doença em todas as faixas etárias, sendo um dos recursos mais utilizados pela saúde ocupacional para proteção específica dos trabalhadores. A prática de vacinação envolve diversos aspectos técnicos científicos e operacionais, que dizem respeito aos agentes imunizantes e à pessoa a ser imunizada (CARVALHO, 2014).

O esquema é realizado em três doses, com intervalo de um mês entre a primeira e a segunda dose e de seis meses entre a primeira e a terceira dose $(0$, 1 e 6 meses). Qualquer esquema iniciado anteriormente e não completado não deve ser reiniciado e sim, completado independente do tempo decorrido entre a primeira dose até a atualização (BRASIL, 2001).

A vacina é preparada por método de engenharia genética por meio da recombinação do DNA, adsorvido em Hidróxido de Alumínio e Timerosal como conservante. Apresenta-se de forma líquida em ampola individual ou frasco-ampola com múltiplas doses. Não há restrição de idade para aplicação da vacina, mas na rotina do Programa Nacional de Imunizações (PNI) está indicada para a faixa etária de 0 a 19 anos, já para a indicação em situação ocupacional, não há restrição de idade (SILVA, 2010).

A exposição do trabalhador a este tipo de vírus se dá através de contato com mucosas ou percutâneas de indivíduos contaminados, sendo esta uma das principais doenças ocupacionais, pois necessita de pequena quantidade de sangue para que a infecção seja transmitida (FERREIRA; SILVEIRA, 2004). A Hepatite $B$ é a doença mais prevalente entre os enfermeiros, pois o Vírus da Hepatite B ou Hepatitis B Virus (HBV) é altamente resistente ao meio, sendo que no sangue seco sobrevive mais de uma semana em temperatura ambiente e não morre exposto a álcool e detergente. Portanto os profissionais possuem alto risco de contágio, pois muitas vezes não lembram ou não recordam de exposições sofridas com fluídos corpóreos contaminados que acabam inoculando o HBV (GARCIA; FACCHINI, 2008). 
No Brasil, a vacinação contra a Hepatite B é recomendada para recémnascidos, adolescentes até 19 anos e pessoas com risco acrescido para adquirir a infecção, entre elas os trabalhadores da saúde (GARCIA; FACCHINI, 2008). Porém muitos indivíduos vacinados (10 a 20\%) acabam não adquirindo o título de protetores de anticorpos, sendo que para os trabalhadores da área da saúde, o Ministério da Saúde (MS) preconiza uma dosagem mínima de anticorpos para o controle (GARCIA; BLANCK; BLANCK, 2007).

Sendo assim, o presente estudo possui o objetivo de conhecer o esquema vacinal contra Hepatite B dos profissionais de enfermagem de um hospital de médio porte do interior do Rio Grande do Sul, Brasil.

\section{MATERIAL E MÉTODO}

Trata-se de um estudo observacional, documental, no qual foi levantado o esquema vacinal dos trabalhadores de enfermagem de um hospital de médio porte do interior do Rio Grande do Sul, Brasil. O estudo foi realizado nos documentos dos profissionais de enfermagem que registram o esquema vacinal dos mesmos junto ao Serviço Especializado em Medicina do Trabalho (SESMT) da instituição.

Inicialmente solicitou-se à instituição hospitalar $\mathrm{o}$ acesso dos pesquisadores aos documentos dos profissionais de enfermagem onde ficam registrados os esquemas vacinais. Na ocasião os pesquisadores apresentaram os objetivos da pesquisa, bem como asseguraram os critérios éticos que estão presentes em todo o processo, obtendo liberação para os documentos.

Em posse da carta de anuência, os pesquisadores se deslocaram ao setor de SESMT, onde com o auxílio do profissional responsável pelo registro, realizaram a coleta de informações iniciais, que ocorreu durante o segundo semestre de 2015. Foram identificados todos os esquemas vacinais dos 268 profissionais de enfermagem (enfermeiros, técnicos em enfermagem e auxiliares em enfermagem) atuantes no local.

A partir deste momento os pesquisadores identificaram os esquemas vacinais de Hepatite $\mathrm{B}$ dos respectivos profissionais e catalogaram as informações em documento Microsoft Excel. Os dados foram posteriormente analisados e utilizados para a confecção de uma tabela para demonstrar os achados neste estudo.

A pesquisa contemplou os aspectos éticos previstos pela Resolução 466 de 2012, a qual define os parâmetros para realização de pesquisas com seres humanos. Neste sentido, o presente estudo utilizou-se de documentos administrativos, não oferecendo riscos éticos ou morais aos envolvidos. 


\section{RESULTADOS E DISCUSSÃO}

Tendo em vista que muitos estudos realizam testes em laboratório, cabe esclarecer que o objetivo deste foi conhecer o esquema vacinal dos profissionais de enfermagem, por meio do controle realizado pela instituição, por meio de um processo documental, fazendo uso dos testes realizados e cadastrados pelo próprio serviço. Portanto não foram realizados exames e avaliações ou considerados fatores como idade, sexo (gênero), ou períodos pós-vacinação, presentes em outros estudos. Da mesma forma não foram relevadas neste estudo, condições clínicas comprometedoras do Sistema Imunológico, tais como o Alcoolismo, Tabagismo a Síndrome da Imunodeficiência Adquirida (AIDS), Diabetes Mellitus (DM), Insuficiência Renal Crônica, Neoplasias ou indivíduo em uso de corticosteróides.

Para exemplificar a importância desta informação, cita-se o estudo de Mendonça (2012), que esclarece sobre pacientes com doenças crônicas do fígado, principalmente as de origem alcoólica, onde, frequentemente, as taxas de soroconversão obtidas com o esquema usual de vacinação contra a Hepatite B têm sido inferiores aos indivíduos sadios, ou seja, há uma menor efetividade das taxas de soroconversão da vacinação padrão contra a Hepatite B.

Possuindo como base do estudo os 268 esquemas vacinais dos profissionais de enfermagem, utilizaram-se como referência os níveis séricos de anticorpos estipulados por Oliveira, Silva e Alves (2007), da seguinte forma: menores do que $10 \mathrm{UI} / \mathrm{ml}$ como não-resposta, de 10 a 100UI/mL indicativos de soroconversão, de 100 a 1000UI/mL como soroproteção e superiores a 1000UI/ $\mathrm{mL}$ como hiper-soroproteção. A Tabela 1, nos mostra essas características.

Tabela 1. Níveis séricos de anticorpos anti-HBs*.

\begin{tabular}{l|l}
\hline Valores (UI/mL) & Situação \\
\hline Menores de 10,00 & Não reagente (sem proteção) \\
\hline De 10,00 a 100,00 & Soroconversão \\
\hline Acima de 100,00 & Imunizados (soroproteção) \\
\hline Acima de 1.000,00 & Super imunizados \\
\hline
\end{tabular}

*Tabela adaptada pelos pesquisadores (2017).

A Tabela 2 descreve os dados levantados pela pesquisa. É possível verificar que $9,10 \%$ dos indivíduos apresentaram soroconversão e que $46,27 \%$ dos indivíduos apresentaram soroproteção, sendo considerados imunizados. 
Tabela 2. Relação entre valores, situação dos exames, número e porcentagem dos profissionais

\begin{tabular}{c|l|c|c}
\hline \multicolumn{1}{c|}{ Valores } & Situação dos exames & $\mathbf{n}$ & $\mathbf{\%}$ \\
\hline Menores de 10,00 & $\begin{array}{l}\text { Não reagente (repetindo esquema } \\
\text { vacinal) }\end{array}$ & 2 & 00,75 \\
\hline De 10,00 a 100,00 & $\begin{array}{l}\text { Deve ser confirmado com exame até } \\
\text { 30 dias }\end{array}$ & 78 & 29,10 \\
\hline Acima de 100,00 & Imunizados & 124 & 46,27 \\
\hline Acima de 1.000 & Super imunizados & 54 & 20,15 \\
\hline- & Não se imunizam & 6 & 02,24 \\
\hline- & Não tem resultado de exames & 3 & 01,12 \\
\hline- & Portador de hepatite B & 1 & 00,37 \\
\hline & TOTAL & $\mathbf{2 6 8}$ & $\mathbf{1 0 0 , 0 0}$ \\
\hline
\end{tabular}

*Resultados da pesquisa 2015.

A média de anticorpos entre os participantes foi de 590,35UI/mL, analisando a Tabela 2 constata-se a aplicação do esquema vacinal antiHBV de acordo com o planejamento estratégico do programa de vacinação estabelecido pelo Ministério da Saúde (2002) em âmbito nacional que implica primeiramente no conhecimento sobre o problema da hepatite e seus impactos sobre a sociedade. Segundo Vranjac (2006), os profissionais de saúde recebem o esquema clássico de três doses ( $0,1,6$ meses ou 0, 1, 4 meses). Após esta etapa um a dois meses após a última dose - é recomendada a realização de sorologia para avaliação da soroconversão (anti-HBsAG $\geq 10 \mathrm{UI} / \mathrm{ml}$ ).

O primeiro aspecto a considerar foi a soroconversão presente em $29,10 \%$ dos indivíduos e a soroproteção ocorrendo em 46,27\%. Em estudo semelhante com 40 indivíduos saudáveis Oliveira, Silva e Alves (2007), obtiveram soroconversão em $6 / 40$, ou $15,0 \%$ e soroproteção em $21 / 40$, ou $52,5 \%$ dos testados. Petry e Kupek (2006), utilizando como valor de corte 10UI/L, obtiveram uma média de efetividade de de $88,7 \%$, semelhante aos $95,52 \%$ dessa pesquisa. E para o valor de corte de 100UI/L foi obtida a efetividade média de $69,3 \%$, semelhante aos $66,42 \%$ do presente estudo.

Outro aspecto a ponderar foi o número considerável de indivíduos, n=54 ou 20,15\% dos participantes que possuem concentrações de anti-HBs hiper-protetoras (superiores a 1000UI/mL). Valores correspondentes foram observados nos estudos de Oliveira, Silva e Alves (2007) e Domingues, Cota e Silva (2010) realizado com profissionais da área da saúde atuantes em uma unidade hospitalar.

O Ministério da Saúde (2002) previa que 15\% da população já estiveram em contato com o HBV e que $1 \%$ apresente a doença permanente associada a esse vírus, ou quadro agudo grave (fulminante). Segundo dados do IBGE 
(2015), a projeção para a população brasileira em novembro do mesmo ano foi de aproximadamente 205.000 .000 de habitantes. São, portanto, $1 \%$ de contaminados, o que representa em torno de 2.050 .000 indivíduos. Já no hospital, o número $\mathrm{n}=1$ de portadores de Hepatite $\mathrm{B}$, representa $0,37 \%$ do total de indivíduos. É um valor $170 \%$ menor do que a média nacional que pode ser questionado, como uma discrepância, sob o ponto de vista estatístico no qual se baseiam as projeções do MS.

Sobre o resultado obtido Coutinho e Cunha (2005), esclarecem que em toda a probabilidade, o valor de $\mathrm{p}$ (nível de significância) irá variar entre 0 e 1 , e que na maioria das áreas científicas, admite-se um erro definido por um p menor ou igual a 0,05 , ou seja, assume-se como margem de segurança $5 \%$ de chances de erro, ou olhando por outro ângulo, 95\% de chances de estar certo. Garcia e Fachinni (2008), em estudo sobre vacinação contra a Hepatite B entre trabalhadores da Atenção Primária à Saúde (APS) utilizaram níveis de confiança de $95 \%$ considerando estatisticamente significativas as associações com um valor $\mathrm{p}<0,05$.

Dessa forma se considerarmos um erro estatístico máximo de 0,5\% $(\mathrm{p}<0,05)$ o valor obtido de $0,3 \%$ não estaria compatível com a média nacional. No entanto Paes (1998) esclarece que não devemos interpretar cegamente os resultados estatísticos, sem levarmos em conta o contexto. O fato de um valor estar estatisticamente fora de um intervalo de tolerância, não significa que esteja incorreto, principalmente quando tratamos de comparações entre grandes e pequenos grupos, esta explicação encontramos em Feinstein (1973), Armitage e Berry (1994), Paes (1998).

Segundos os autores não se devem tomar os testes estatísticos como uma verdade para todas as situações a serem avaliadas. O que um profissional da saúde deve questionar ao interpretar os dados de uma pesquisa é se aqueles resultados obtidos são relevantes do ponto de vista clínico do indivíduo. Muitas vezes um resultado estatisticamente não significante pode ser clinicamente importante e vice-versa. Portanto, a importância de um estudo em termos biológicos não deve ser julgada pela estatística, e sim, pelos profissionais da área em que a pesquisa está sendo realizada.

Outro fator a ser avaliado é em relação aos indivíduos não reagentes, onde $2(0,75 \%)$ apresentaram concentração de anti-HBs inferior a 10UI/ $\mathrm{ml}$. Uma explicação para o ocorrido se dá ao fato de que aproximadamente $12 \%$ dos adultos serem, aparentemente, imunocompetentes, ou seja, seus organismos são incapazes de uma resposta imunológica considerada protetora após a vacinação, onde os níveis de anticorpos apresentam-se menores do que 10UI/ml. Antunes, Macedo e Estrada (2004) obtiveram em sua pesquisa níveis não protetores de anti-HBs em 38 (12,21\%) dos 311 voluntários que participaram do estudo. Nesses casos são recomendados reforços para indivíduos imunocompetentes, com exceção de crianças com idade inferior a um ano (VRANJAC, 2006). 
As categorias da Tabela 2: "Não se imunizam" com seis (06) profissionais $(2,24 \%)$ e "Não tem resultado de exames" com três (03) profissionais $(1,12 \%)$ representam uma não adesão de 3,36\%. Em importante estudo de revisão integrativa de 19 artigos publicados, que abordou a identificação de evidências na literatura sobre o índice de adesão à imunização contra Hepatite B por profissionais e estudantes da área da saúde, Milani e colaboradores (2011), verificaram uma taxa de adesão à vacinação que variou de $26,7 \%$, a $95,5 \%$. A maior taxa de adesão $(95,5 \%)$ foi encontrada entre profissionais de saúde.

Luz et al. (2004) observaram em seu estudo que 95\% dos participantes realizaram o esquema de vacinação completo. Prado-Palos et al. (2006); Moreira et al. (2007); Garcia e Fachini (2008), constataram médias de até 13,5\% de indivíduos que não completaram as três doses do esquema vacinal necessário para a obtenção da imunidade contra Hepatite B, observando ser um fato frequente a não realização do ciclo de vacinação.

Milani et al. (2011), citam que a vacina disponível no próprio emprego e sua gratuidade é fator contribuinte para melhor adesão. E para a baixa adesão foram o custo elevado da vacina, descrédito quanto ao seu benefício e pouco investimento em campanhas de vacinação. Outro fator que pode vir a contribuir para os resultados positivos do esquema vacinal do hospital, assim como a média de anticorpos de 590,35UI/mL, é a média de idade de 32,5 anos dos funcionários.

Vranjac (2006), explica que boa imunogenicidade e a eficácia das vacinas contra Hepatite B, com proteção em mais de $90 \%$ dos adultos jovens sadios e mais de $95 \%$ em lactentes, crianças e adolescentes vem sendo há muito demonstrada por diversos estudos. No entanto, a eficácia diminui gradativamente após os 40 anos de idade. A obesidade, o estresse, o tabagismo e o etilismo também são fatores associados a uma menor eficácia vacinal (VRANJAC, 2006).

Entretanto, Domingues, Cota e Silva (2010), ao cruzarem valores de concentração de anticorpos com a idade dos indivíduos por meio da Correlação de Spearman demonstraram, então, que não houve correlação $(p<0,1)$ entre a idade e o nível de anti-HBs, uma vez que indivíduos acima de 50 anos obtiveram níveis mais altos em relação a outros com a idade entre 24 e 28 anos. Esse resultado indica que determinadas condições não podem ser atreladas apenas a um fator isolado, mas à combinação de mais fatores influentes do meio em que as pesquisas são realizadas.

No presente estudo a média de anticorpos entre os informantes foi de 590,35UI/mL. Oliveira, Silva e Alves (2007), obtiveram média dos níveis séricos de anti-HBs entre os pacientes que responderam à vacinação no grupo de alcoolistas ( $511 \pm 448 \mathrm{UI} / \mathrm{mL}$ ), e no grupo controle, composto por indivíduos sadios $(696 \pm 410 \mathrm{UI} / \mathrm{mL})$. 


\section{CONCLUSÕES}

Analisando os dados da pesquisa, se pode concluir que o esquema vacinal contra a Hepatite B está sendo aplicado pela instituição, sendo observada uma alta taxa de adesão dos funcionários (96,27\%). Estudos envolvendo a vacinação anti-HBs devem levar em conta o maior número possível de fatores para a determinação de suas análises, evitando formas isoladas de poucas variáveis incidentes que trazem resultados imprecisos.

Verificou-se que é importante a vacinação contra HBV para a segurança dos profissionais da área que convivem com o constante risco de contato. Mas além da vacinação, que deve seguir a recomendação de três doses, é importante a realização da dosagem de anti-HBs após a vacinação, em função da resposta específica de cada organismo que pode não gerar níveis protetores de anticorpos, sendo necessárias novas doses de reforço.

\section{REFERÊNCIAS}

ANTUNES, H.; MACEDO, M.; ESTRADA, A. Taxa de cobertura vacinal com imunização para o vírus da hepatite B. Rev. Acta Médica Portuguesa, Lisboa, v. 17, p. 303-308, 2004.

ARMITAGE, P.; BERRY, G. Statistical Inference. In: Statistical Methods in Medical Research. 3 rded. Oxford: Blackwell, 1994.

BRASIL. Manual de Normas de Vacinação. Fundação Nacional de Saúde. 3. ed. Brasília: Ministério da Saúde, jun. 2001. 580p.

BULHÕES, I. Riscos do trabalho de enfermagem. 2. ed. Rio de Janeiro: Luna, 1998.

CARVALHO, G. M. Enfermagem do Trabalho. 2. ed. São Paulo: Guanabara Koogan, 2014.

COUTINHO, E. S. F.; CUNHA, G. M. Conceitos básicos de epidemiologia e estatística para a leitura de ensaios clínicos controlados. Rev. Bras. Psiquiatr. v. 27, n. 2, p. 146151, 2005.

DOMINGUES, B. D.; COTA, G. S.; SILVA, R. M. M. Avaliação da resposta imunológica à vacinação para hepatite $b$ em profissionais de laboratórios de análises clínicas no município de Timóteo/ MG. Farmácia \& Ciência, v.1, p.41 -51 , ago./dez, 2010.

FEINSTEIN, A. R. Clinical bioestadistics. XX. The epidemiologic trohoc, the ablativo risk ratio, and retrospective research. Clinical Pharmacology and Therapeutics, v. 14, p. 291-307, 1973.

FERREIRA, C. T.; SILVEIRA, T. R. Hepatites virais: aspectos da epidemiologia e da prevenção. Rev. bras. epidemiol. v.7, n.4, p. 473-487, 2004. 
GARCIA, L. P.; BLANK, V. L. G.; BLANK, N. Aderência a medidas de proteção individual contra a hepatite $B$ entre cirurgiões-dentistas e auxiliares de consultório dentário. Rev. bras. epidemiol. v.10, n.4, p. 525-535, dez. 2007.

GARCIA, L. P.; FACHINI, L. A. Vacinação contra hepatite B entre trabalhadores da atenção básica à saúde. Cad. Saúde Pública, Rio de Janeiro,v. 24, n. 5, p. 1130-1140, mai. 2008.

INSTITUTO BRASILEIRO DE ECONOMIA E ESTATÍSTICA - IBGE. População do Brasil. Projeção, População, nov. 2015.

LUZ, J. A. et al. Soroprevalência das infecções pelos vírus das hepatites B e C em profissionais de hemodiálise do Tocantins. Rev. Patologia Tropical, Goiânia, v. 33, n1, p. 119-123, jan./jun. 2004.

MENDONÇA. J. S. Vacinação em pacientes com doença hepática crônica. Cartilha. Programa de Educação Médica Continuada, Sociedade Brasileira de Hepatologia, p. 3-6, 2012.

MILANI, R. M. et al. Imunização contra hepatite B em profissionais e estudantes da área da saúde: revisão integrativa. Rev. Eletr. Enf. v. 13, n. 2, p. 323-30, abr./jun. 2011.

MINISTÉRIO DA SAÚDE. Avaliação da Assistência às Hepatites Virais no Brasil, 2002.

MOREIRA, R. C. et al. Soroprevalência da hepatite B e avaliação da resposta imunológica à vacinação contra a hepatite $\mathrm{B}$ por via intramuscular e intradérmica em profissionais de um laboratório de saúde pública. J. Bras. Patol. Med. Lab., Rio de Janeiro, v. 43, n. 5, p. 313-318, 2007.

OLIVEIRA, L. C. M.; SILVA, T. E.; ALVES, M. H. Resposta à vacinação contra a hepatite $\mathrm{B}$ em alcoolistas sem cirrose hepática clinicamente evidente. Arq. Gastroenterol, v.44, n.3, p. 195-200. jul./set. 2007.

PAES, Â. T. Itens essenciais em bioestatística. Arq. Bras. Cardiol. v.71, n.4, p. 575-580, 1998.

PETRY, A.; KUPEK, E. J. Efetividade das vacinas anti-VHB (DNA-recombinante) em doadores de sangue de uma região endêmica para hepatite B no sul do Brasil, Rev.

Soc. Brás. de Medicina Tropical. Uberaba, v. 39, p.462-466, set./out, 2006.

PRADO-PALOS, M. A. et al. Acidentes com material biológico ocorridos com profissionais de laboratório de análises clínicas. J. Bras. Doenças Sex. Transm., Niterói, v.18, n. 4, p. 231-234, 2006.

SILVA, R. M. et al. Asma em funcionários de hospital geral. Rev. Pulmão, Rio de Janeiro, v.16, n. 1, p. 17-20, 2007.

TOSCANO, C.; KOSIM, L. Cartilha de vacinas: pra quem quer saber mesmo das coisas. Brasília: Organização Pan-americana de Saúde, 2003.

VRANJAC, A. Vacina contra a Hepatite B. Boletim Epidemiológico Paulista, São Paulo, v. 3, n. 33, set. 2006. 